\title{
COVID-VAC: The second global study of COVID-19 vaccine acceptance
}

\section{Jeffrey Lazarus ( $\sim$ Jeffrey.Lazarus@ISGlobal.org )}

Barcelona Institute for Global Health (ISGlobal) https://orcid.org/0000-0001-9618-2299

\section{Katarzyna Wyka}

Graduate School of Public Health \& Health Policy, City University of New York (CUNY)

\section{Trenton White}

Barcelona Institute for Global Health (ISGlobal), Hospital Clínic, University of Barcelona, Barcelona https://orcid.org/0000-0002-0633-4445

\section{Camila Picchio}

Barcelona Institute for Global Health (ISGlobal), Hospital Clínic, University of Barcelona, Barcelona

\section{Kenneth Rabin}

City University of New York (CUNY) Graduate School of Public Health \& Health Policy, New York

\section{Scott Ratzan}

City University of New York (CUNY) Graduate School of Public Health \& Health Policy, New York

\section{Jeanna Parsons Leigh}

Dalhousie University

Jia Hu

University of Calgary

\section{Ayman El-Mohandes}

City University of New York (CUNY) Graduate School of Public Health \& Health Policy, New York

\section{Article}

Keywords: COVID-19, disease control, SARS-CoV-2, vaccination

Posted Date: August 14th, 2021

DOl: https://doi.org/10.21203/rs.3.rs-780128/v1

License: (9) This work is licensed under a Creative Commons Attribution 4.0 International License. Read Full License

Version of Record: A version of this preprint was published at Nature Communications on July 1st, 2022. See the published version at https://doi.org/10.1038/s41467-022-31441-x. 



\section{COVID-VAC: The second global study of COVID-19 vaccine acceptance}

Jeffrey V Lazarus ${ }^{1,2^{*}}$, Katarzyna Wyka ${ }^{2}$, Trenton M White ${ }^{1}$, Camila A Picchio ${ }^{1}$, Kenneth Rabin ${ }^{2}$, Scott C Ratzan², Jeanna Parsons Leigh ${ }^{3}$, Jia Hu ${ }^{4}$, Ayman El-Mohandes ${ }^{2}$

1. Barcelona Institute for Global Health (ISGlobal), Hospital Clínic, University of Barcelona, Barcelona, Spain

2. Graduate School of Public Health \& Health Policy, City University of New York (CUNY), New York, New York, United States

3. School of Health Administration, Dalhousie University, Halifax, Canada

4. University of Calgary, Calgary, Canada

* Corresponding Author: Jeffrey V Lazarus, jeffrey.lazarus@isglobal.org

\section{Abstract (150/150 words)}

This one-year follow-up study investigated COVID-19 vaccine acceptance in 23 countries. In June $2021,75.2 \%$ of respondents reported to accept the vaccine, of which $49 \%$ had received at least one vaccine dose and $51 \%$ were willing to get it once available to them. Factors associated with COVID19 vaccine acceptance include perceived safety and trust in science, as measured by a novel COVIDVAC score, and personal experience with COVID-19. Males, healthcare workers, well-to-do people, those with university degrees, and those whose physician recommended vaccination were more likely to accept it. Trust in governmental ability to address COVID-19 was weakly associated with vaccine acceptance. Respondents strongly supported vaccination to travel internationally, but weakly supported vaccinating children for school attendance. Hesitancy rates remain high in LMICs. Health policymakers should aggressively communicate vaccination need and inform accurately about efficacy and safety compared to disease risk, and healthcare workers need a greater vaccine communications role.

Keywords: COVID-19, disease control, SARS-CoV-2, vaccination 


\section{Introduction}

Vaccine hesitancy is a global challenge, declared by the World Health Organization in 2019 as one of the ten greatest global health threats ${ }^{1}$, and a vital concern since vaccination is the most effective intervention to control the ongoing COVID-19 pandemic. In June 2020, as most countries were experiencing a second wave of SARS-CoV-2 transmission, the authors of this study reported potentially low COVID-19 vaccine acceptance among more than 13,000 respondents in 19 of the hardest-hit countries. ${ }^{2}$ As of 1 August 2021, 1.07 billion individuals globally had received one dose and another 1.14 billion received two doses of an available COVID-19 vaccine; however, more than $70 \%$ of the world (90\% in low- and middle-income countries (LMIC)) remains unvaccinated. ${ }^{3}$

Globally, rates of COVID-19 vaccine acceptance vary. In a 2021 study of more than 30,000 respondents from eight countries, $27 \%$ of participants were hesitant, ranging from $9.6 \%$ in Brazil to 47.3\% in France. ${ }^{4}$ Another survey of more than 18,000 respondents from 15 countries reported a range of $54 \%$ vaccine acceptance in France to $87 \%$ in India. ${ }^{5} \mathrm{~A}$ recent review of 15 peer-reviewed studies calculates a COVID-19 vaccine acceptance rate of $77.6 \%$ in the general population and $86.1 \%$ among students. ${ }^{6}$ Another study reported vaccine acceptance ranges from $23.6 \%$ in Kuwait to $97 \%$ in Ecuador. ${ }^{7}$ The lowest rates of acceptance to date are reported in the Middle East, Africa, and several European countries (notably France, Italy, Poland, and Russia).

The main causes of vaccine hesitancy in these studies included concerns about vaccine safety and efficacy, mistrust of governments and health and scientific institutions, individual religious and political beliefs, as well as misinformation and conspiracy theories. ${ }^{8-11}$ Most studies reported men to be more likely to accept COVID-19 vaccines than women. ${ }^{7}$ Other variables associated with lower vaccine acceptance include living in rural areas and lower income. Conversely, COVID-19 vaccine acceptance correlated strongly among those who reported greater concern about the effects of 
COVID-19 disease and those previously vaccinated against influenza. ${ }^{4}$ Posessing accurate knowledge about COVID-19 disease transmissibility and prevention, fear of contracting COVID-19, and higher income all correlated positively with acceptance, but having a chronic disease and being female did not. ${ }^{12}$ The association between age and vaccine acceptance varied geographically, with some studies showing greater acceptance among older (above 65 years) ${ }^{4}$ and others among younger (below 40 years) age groups. ${ }^{12} \mathrm{~A}$ survey conducted in nine LMICs in Asia and Africa showed that vaccine acceptance increased with a higher perception of effectiveness; $76.4 \%$ accepting a hypothetical $90 \%$ effective vaccine increased to $88.8 \%$ accepting if $95 \%$ effective. ${ }^{12}$

Following a year of substantial but very uneven global availability, administration and acceptance of COVID-19 vaccines, further investigation is necessary to understand how knowledge, risk perception, trust, and other factors associated with acceptance continue to evolve. The present study was undertaken in June 2021 to assess vaccine acceptance and uptake among 23 countries that represent approximately $60 \%$ of the world's population. In addition, comparisons in acceptance rates among the 19 countries in our 2020 study were included. Novel investigations in this 2021 study include testing the predictive value of a new vaccine acceptance score (COVID-VAC), which represents perceptions of risk, trust, safety, equity, and efficacy; the impact of mental health on vaccine acceptance; and acceptance for a range of requirements for proof of vaccination, and vaccination for children.

\section{Results}

Sample characteristics

23,000 participants from 23 countries responded to the survey. Approximately half were female (50.2\%), ages 30-59 (59.9\%), and resided in LMICs (52.2\%). One-fifth were university graduates (22.4\%) (Table 1). Healthcare workers represented 10.8\% of respondents. COVID-19 illness (self or 
family) or loss of a family member to COVID-19 were most common in Ecuador (48.3\% and 19.2\%), Brazil (38.3\% and 18.3$)$ and Peru (35.5\% and $34.7 \%)$, and least common in China (1.5\% and $2 \%)$, Singapore (3.3\% and 5.3\%), South Korea (3.8\% and 2.1\%), Ghana (5.8\% and $1.5 \%)$, and Nigeria (6\% and 2.3\%). Loss of income was highest in lower-middle and upper-middle income countries (range $31.7 \%$ in Germany to $95.1 \%$ in Ecuador). Reported anxiety prevalence ranged from $9.2 \%$ in Ghana to 44.7\% in Turkey, and depression was lowest in China (12.6\%) and Ghana (12.9\%) and highest in Turkey (38.7\%).

Vaccine acceptance, June 2021

In June 2021, global COVID-19 vaccine acceptance was $75.2 \%$, of whom $49 \%$ reported having received at least one vaccine dose and $51 \%$ were willing to get it once available to them (Figure 1). Reported vaccine acceptance was highest in China (97.6\% (of whom 91.9\% had received at least one dose)), Canada (79.2\% (86.3\%)), and the UK (81.2\% (82.6\%)) and lowest in Russia (51.6\% (30.4\%)), Nigeria (57\% (3.5\%)), and Poland (59.3\% (74.2\%) (Figure 1). The mean difference between these single-dose figures and official rates ${ }^{13}$ was $2.7 \%$; reliable data for China are unavailable.

Compared to June 2020, vaccine acceptance in the 19 countries previously surveyed increased from $71.5 \%$ to $75.2 \%$, though an opposite trend was observed in South Africa $(-20.9 \%)$, the US (-8.8\%), Nigeria (-8.2\%), and Russia (-3.3\%). Vaccine acceptance when recommended by employer increased in all countries (global average increased from $48.1 \%$ in 2020 to $64.2 \%$ in 2021), except in Germany ($3 \%$ ) and South Korea (-0.2\%). Vaccine acceptance when recommended by one's doctor (range $56.4 \%$ in Russia to $95.1 \%$ in China), was higher in all countries compared to one's employer (range $44.4 \%$ in Russia to $96.7 \%$ in China) . Notably, among respondents unsure/unwilling to vaccinate, potential vaccine acceptance was most likely if recommended by one's doctor, particularly in India (63.5\%), Kenya (38\%), Brazil, (36.8\%), Turkey(29.9\%), South Korea (28.4\%), and Russia (26.5\%). Generally, 
those unsure/unwilling to take the vaccine were more likely to follow their doctors' recommendation $(21.9 \%+/-12.3 \%)$ than employers' recommendation $(13.2 \%+/-7.7 \% ; p=0.006)$ (Figure 1).

Vaccine acceptance correlated highly with perceptions of risk, trust, safety, equity, and efficacy, measured using COVID-VAC (June 2021: $r=0.85, p<0.001$ ). In validation analyses, COVID-VAC was unidimensional with a Cronbach's alpha of 0.86 . Vaccine acceptance weakly correlated with countries' current COVID-19 case burden ( $r=-0.13, p>0.05)$, mortality $(r=-0.25, p>0.05)$, and approval of government responses to the pandemic in June 2020, measured using COVID-SCORE-10 ${ }^{11}(r=0.25$, $p>0.05$ ) (Figure 2).

Countries' vaccination rates ${ }^{13}$ and hesitancy showed moderate negative association ( $r=0.45$, $\mathrm{p}=0.034$ ) (Figure 2). Generally, countries in Africa had low vaccination uptake and high hesitancy; whereas India, South Korea, and countries in South America had higher uptake and lower hesitancy. Countries with $40 \%+$ uptake had similar hesitancy to the latter group, with the exception of Poland, France and the US, which had high hesitancy.

Parents' willingness to vaccinate children was highest in China (95\%), Brazil (91.3\%), Ecuador (85.9\%), Peru (85.1\%) and lowest in Russia (35.5\%), Poland (46.3\%) and France (48.5\%). In all countries, willingness to vaccinate one's children was significantly greater among parents who accepted the vaccine $(p<0.001)$ (Figure 3$)$.

Correlates of vaccine acceptance June 2021

In multivariable models, vaccine acceptance was associated with older respondents in Canada, France, Germany, South Korea, Sweden, UK, and US (aOR range, 1.02-1.04) (Figure 4) and younger 
ones in Nigeria $(\mathrm{aOR}=0.89)$ and Ghana $(\mathrm{aOR}=0.93)$. Male gender was significantly positively correlated in Ghana, Nigeria, South Africa, and the US (aOR range 1.51-8.84) and female gender in Kenya and Peru ( $\mathrm{aOR}=0.39$ and $\mathrm{aOR}=0.32)$. Having a university degree was significantly associated with vaccine acceptance in France, Mexico, South Africa, and the US (aOR range, 1.75-5.55). Personal or family COVID-19 illness or death of a family member due to COVID-19 was strongly assocated with vaccine acceptance, with statistically significant associations with personal or family illness in Germany, Peru, Poland, Turkey, Singapore, UK (aOR range 1.89-5.72) and with loss of a family member in Brazil, France, Germany, Ghana, Mexico, Peru, Poland, Sweden, Turkey and the UK (aOR range 2.75-9.25). Having low or no income was associated with less vaccine acceptance in Brazil, France, Germany, Nigeria, Peru, Russia, South Korea, Spain, Turkey, and the US (aOR range 0.080.55). Moderate or severe income loss due to the pandemic was positively associated with vaccine acceptance in Ghana, Nigeria, Poland, and the US (aOR range 2.01-6.27).

Adjusted for socio-demographic factors and COVID-19 experience, the COVID-VAC score was the most salient and consistent positive correlate of vaccine acceptance in all countries (aOR range, 1.41-3.44) (Figure 5). The strongest correlation was with "I trust the science behind the COVID-19 vaccines" and "safety of the vaccines." The lowest correlation was with "I trust my government is able to deliver the vaccine to everyone and everywhere in my country" (Supplemental Table 1). In univariable analyses, vaccine acceptance was significantly higher among respondents who reported that they trust their central and/or local government. This finding was not universal, however, and was not found in Brazil, China, Ecuador, and Peru (Supplemental Figure 1). After adjustment, trust in central government had a significantly positive association in Russia and Singapore (aOR=2.05 and $\mathrm{aOR}=5.28$ ) and trust in local government had a negative association in South Africa (aOR=0.44). In Poland, vaccine acceptance was negatively correlated with trust in central government $(\mathrm{aOR}=.48)$ and positively correlated with trust in local government $(\mathrm{aOR}=2.9)$. Finally, vaccine acceptance positively correlated with anxiety in Canada $(\mathrm{aOR}=4.59)$ and Peru (aOR=3.64) and negatively 
correlated in South Korea $(\mathrm{aOR}=.43)$ and the US ( $\mathrm{aOR}=.31)$, while depression was a negative factor in Canada (aOR=.21) and South Africa (aOR=.53) (Figure 5).

Healthcare workers (HCW)

Vaccine acceptance was significantly higher among HCWs globally compared to non-HCWs $(91.8 \%$ vs. $83 \%, p<0.001, a O R=1.72,95 \% \mathrm{Cl}[1.38,2.13]$ ) (Table 2). Vaccine hesitancy was significantly lower among physicians (3.1\%) followed by nurses (6.5\%), community health workers (7.8\%), and other HCWs (14.0\%).

\section{Proof of vaccination requirements}

Support for requiring vaccines was highest in China, India, Peru and South Korea and lowest in Poland, Russia and Germany. Strong support was reported globally (74.4\%) for proof of vaccination to travel internationally, particularly in China (93.3\%), South Korea (87.8\%), India (87.7\%), Brazil (86.4\%), and Ecuador (83\%), with less support in Poland (52.7\%) and Russia (52.5\%). Overall support was $63.3 \%$ and $63.1 \%$ for vaccination to attend university and indoor activities, respectively. These ranged from lows in Russia of $33.1 \%$ for university and $37.6 \%$ for indoor activitiesto highs in China of $95.4 \%$ and $89.7 \%$. Support for governments or employers to require vaccination followed similar trends. Agreement with mandates to vaccinate school children received the lowest support overall (58.2\%), ranging from $24.4 \%$ in Russia to $86.6 \%$ in China (Figure 6).

\section{Discussion}

Reported COVID-19 vaccine acceptance, measured by intention to get vaccinated or having received at least one dose of an available vaccine, increased over the last year in 15 of the 19 countries studied both years and was $75.2 \%$ for the 23 countries studied in 2021 , still below what is needed to 
achieve global herd immunity (80-85\%). Among the six-item COVID-VAC score, positive perceptions of safety and trust in the science behind vaccine development were the strongest predictors of acceptance, while perceptions of efficacy, benefit, and equity also held strong associations. Other determinants of vaccine acceptance varied by country; personal experience with COVID-19 (e.g. sickness or loss of a family member) predominated, but other demographic characteristics (e.g. gender, education and income) showed varying degrees of association, and government trust was associated with vaccine acceptance in a few countries.

In order to improve the global vaccination rate, some countries may require people to present proof of vaccination to attend work, school, or indoor activities and events. Our results found the strongest support for requirements targeting international travellers and support was weakest for requirements for school children. Importantly, vaccine acceptance improves among those indicating unwillingness to vaccinate if it is recommended by a doctor, and to a lesser extent by an employer.

Misperceptions of vaccines as having high risks and low benefits drive vaccine hesitancy, ${ }^{14}$ which may also be influenced by lower trust in the science behind vaccine research and production. ${ }^{15-19} \mathrm{In}$ late 2019 and early 2020 the majority of people in most countries preceived the importance of science and trust in scientists positively. ${ }^{20}$ Our results corroborate these findings where perceptions of trust in science and vaccine safety were most predictive of vaccine acceptance.

Healthcare workers are in a privileged position of trust and are therefore important sources of reliable and accurate vaccine information. ${ }^{21-24}$ Among HCWs, COVID-19 vaccine hesitancy ranged between $4.3 \%$ and $72 \%$, with an average of $22.5 \% .{ }^{25}$ Similar to the general population, the main reasons for vaccine hesitancy among HCWs were concerns about efficacy, safety, and potential sideeffects. Demographic factors among HCWs such as male gender, older age and holding a doctoral degree were positively associated with acceptance of COVID-19 vaccines. ${ }^{25}$ Our study aligns with 
similarly recorded trends of higher rates of vaccination acceptance among physicians compared to nurses. ${ }^{26-29}$ Among hesitant respondents in this survey, the advice of their physician was the factor most likely to change their minds, followed by the recommendation of their employer. This effect could be amplified if the physician had personally received the vaccine.

In June 2020 , trust in government to successfully address unexpected health threats, including the COVID-19 pandemic, was one of the strongest factors associated with acceptance of an (at that time) unavailable vaccine. ${ }^{2}$ A 2020 study in Portugal, where $56 \%$ reported they would wait to take the COVID-19 vaccine and 9\% would refuse, showed that vaccine hesitancy was related to a poor perception of government and health service response as well as a lack of trust in the information provided, ${ }^{30}$ which is consistent with previous pandemic research. ${ }^{31}$ Yet, after accounting for sociodemographic, vaccine-specific, and COVID-19 experience variables, our study found trust in central government to be significantly associated with vaccine acceptance only in Russia and Singapore and for local government in only Poland. It is notable also that Nigeria reported low vaccine acceptance and high distrust in governmental ability to respond to COVID-19, ${ }^{32}$ but the association was not significant. This dissonance between trust in government and vaccine acceptance in our study could be related to the population's general dissatisfaction with government responses to the pandemic and its economic consequences, with vaccine acceptance being independent of such sentiments and more a reflection of personal experiences with COVID-19 illness or loss of life and livelihood. Our results confirm that direct experience for self or family with the illness, and/or loss of a family member to the disease are independently associated with vaccine acceptance.

As health systems in LMICs struggle to address COVID-19, ${ }^{33}$ vaccine access has become cause for national frustrations. Most LMICs have been slow to receive and distribute vaccines, which are significantly more available in high-income countries, prompting critiques of global vaccine inequity. ${ }^{34}$ 
Most recent studies do not investigate income as a potential influencer on vaccine acceptance. A study conducted in Portugal found people who lost income during the pandemic were more hesitant. ${ }^{30}$ An Irish study showed that people with lower income were also more vaccine hesitant. ${ }^{35}$ In China, loss of income was greater among residents of areas with more severe COVID-19 transmission and magnified existing social and economic disparities. ${ }^{36}$ In the US, having lower income was associated with higher risk of depression during the pandemic. ${ }^{37}$ Our results show a seemingly paradox where lower household income is associated with a greater level of hesitance, while loss of income due to the pandemic is associated with greater likelihood of vaccine acceptance. We suspect the perceived association between vaccination and return to normalcy is stronger among people who lost socioeconomic status due to pandemic-related job loss, while people whose income was low before the pandemic may not perceive a vaccine as making much of a difference in their lives.

Globally, anxiety and depression increased during the pandemic while positive feelings such as happiness and life satisfaction decreased. ${ }^{38} \mathrm{~A}$ global review of COVID-19 related mental health found anxiety levels of $26.5 \%-44.6 \%$, depression rates of $8.1 \%-25 \%$ and insomnia levels of $38 \% .^{39}$ Stress levels were found to greatly differ (3.8\% and 68.3\%). In several countries such as Bangladesh, India, and Pakistancases of suicide as a result of COVID-19 fear have been reported. ${ }^{38}$ Across a range of timepoints and geographies, people who had COVID-19 report more symptoms of anxiety, depression, and post-traumatic stress disorder than people without a COVID-19 diagnosis. ${ }^{38}$ Similarly, people with pre-existing psychiatric conditions reported worsening of their psychiatric symptoms during the pandemic. ${ }^{40}$

Mental illness has been associated with a higher risk of COVID-19 related mortality and morbidity, ${ }^{41}$ yet studies examining the impact of mental health on vaccine hesitancy are scarce. One German 
study did not show a relation between depression or anxiety and vaccine hesitancy. ${ }^{42}$ This is in line with a Danish study showing that, although people previously diagnosed with mental illnesses reported slightly lower vaccine acceptance compared to the general population (84.8\% versus 89.5\%), vaccine hesitancy among people with mental illnesses does not seem to be a deterrant to reaching herd immunity. ${ }^{43}$ In Ireland, by contrast, people who had received treatment for a mental health problem were more accepting of a vaccine, unlike UK respondents who showed no association. ${ }^{35}$ Our study results suggest that the effects of depression and anxiety are far from universal, with divergent associations between anxiety and depression and vaccine acceptance reported across the 23 countries. A deeper examination of cultural influences should be explored in future research.

Increased vaccine scepticism may result from the dissemination of erroneous or inaccurate, and often politicized, ${ }^{17,44}$ information. Misinformation drives vaccine hesitancy, undermining confidence in vaccine safety and efficacy, as well as in equity of availability and access to COVID-19 vaccines. ${ }^{45}$ For example, over two-thirds of vaccine videos on YouTube that were analyzed for content accuracy in May 2019 were found to have presented unreliable safety and efficacy information. ${ }^{46}$ However, in mid-February 2021, despite only $46 \%$ of Twitter poll respondents agreeing that all COVID-19 vaccines are safe, $83 \%$ indicated they would accept a vaccine, while only $2 \%$ would only agree to accept one if it were mandatory to do so ${ }^{47}$ Our results indicate that respondents are willing to trust their doctors' advice. HCWs should play a more direct role in disseminating clear and credible information whenever possible.

To control the COVID-19 pandemic, requirements for proof of vaccination, or vaccine mandates, are being considered, for example, to travel internationally or to attend work, school, or indoor events. A 2020 study surveying 1,200 Australians found that 73\% of the respondents agreed with vaccine mandates for work, travel, and study. ${ }^{48}$ In line with our results, a US September 2020 study found 
that approximately half of the general population considered mandatory COVID-19 vaccination for children attending school acceptable, a perspective that remains universally low in our sample.

Mandates for adults by state governments were considered acceptable by $40.9 \%$ of the US population, whereas $47.7 \%$ accepted mandates by their employer to attend work. ${ }^{49}$ However, our 2020 global study showed that people were potentially more likely to accept voluntary over employer-mandated vaccination. ${ }^{2}$ "Choice architecture" that frames vaccination requirements as effective public health and disease prevention and control tools, which one chooses to accept in order to fully participate in society, as opposed to a violation of the individual's right to select medical treatment, may promote incremental vaccine uptake. ${ }^{50}$ As vaccines receive full approval from regulatory agencies, this may lead to improved perspectives on safety and efficacy, and vaccination campaigns based on such choice framing could convince more unvaccinated adults and young adults to acceopt vaccination and increase parental acceptance of vaccination for their children.

One limitation of correlation analyses using actual vaccination rates is that countries with low vaccine access may produce unreliable results given this extrinsic factor. Additionally, our questionnaire asked about a general COVID-19 vaccine, whereas several COVID-19 vaccines, each with different efficacy results and targeted misinformation, are being distributed globally. This study is strengthened by maintaining a sampling methodology that ensures population representativeness between iterations.

As COVID-19 vaccination campaigns continue and coverage improves, further challenges will include increasing vaccination among those reporting lower vaccine confidence in addition to expanding equitable vaccine access to low- and middle-income countries. Validation of COVID-VAC confirms the importance of positive perception of vaccine safety, efficacy and equity for vaccine acceptance. Vaccine uptake may be improved through targeted requirements for vaccination in order to 
participate in certain activities. Misinformation may have greater opportunity to spread in settings where access to COVID-19 vaccination is low, so accurate COVID-19 vaccine communication should be delivered by trusted sources, like doctors, to promote vaccination and clearly explain its safety and benefits to individuals, families, and communities.

\section{Methods}

Study participants

Participants were recruited by Consensus Strategies using multiple international online panel providers to avoid coverage bias: Dynata provided 22,500 respondents across all 23 countries; and Consensus Strategies provided 500 respondents from Ghana. Respondents' identities were verified using IP addresses and mobile phone numbers. Participants were recruited for the panels via a variety of methods, including online, telephone, and direct mail solicitation and equitably compensated in compliance with ethical standards, varying by country and not exceeding USD 3 per completed survey. No personally identifiable information was collected or stored.

\section{Sampling}

Strata included age (18-29, 30-39, 40-49, 50-59 and 60 years and older); gender (male, female, prefer not to say, and "other"); statistical regions (usually province or state, varies by country); and level of education (based on each country's educational system ${ }^{51}$ ), using global data from UNESCO the Organisation for Economic Co-operation and Development, and country data from Sweden, the United Kingdom, and the United States. Educational level was coded into two groups, those who had or had not completed a university degree. The number of participants who could enrol in each of 
these strata was calculated to reflect the distribution in the general population based on census/survey estimates provided by the World Bank and CIA World Factbook. Data were weighted by strata with each stratum requiring a minimum of 50 participants. Sampling was random and is described in detail elsewhere. ${ }^{51}$

Data collection

Survey data were collected between 25-30 June 2021, from an online panel of 23,000 respondents aged $\geq 18$ years from 23 countries ( $n=1,000$ per country), comprised of those countries included in the 2020 study $^{2}(n=19)$, augmented by four additional countries with high disease incidence ${ }^{52}$ and representing regions not represented in the previous study. The 23 countries are: Brazil, Canada, China, Ecuador, France, Germany, Ghana, India, Italy, Kenya, Mexico, Nigeria, Peru, Poland, Russia, Singapore, South Africa, South Korea, Spain, Sweden, Turkey, the United Kingdom (UK) and the United States (US). This study was approved and the survey administered by Emerson College, Boston, USA (institutional review board protocol no. 20-023-F-E-6/12-[R1] updated April 12, 2021).

\section{Survey Instrument}

The instrument was developed by an expert panel following a comprehensive literature review of COVID-19 vaccine acceptance studies and the authors' earlier studies of pandemic control measures ${ }^{51,53,54}$ and vaccination intent. ${ }^{14,55-60}$ The instrument included 1) a 6-item COVID-VAC score representing perceptions of risk, trust, safety, equity, and efficacy, identified via the literature review as important determinants of acceptance of a COVID-19 vaccine and of routine immunization, 2) vaccination acceptance for self (whether respondent received at least one dose of a COVID-19 vaccine and if not, whether he/she will take the COVID-19 vaccine when it is available for them) and vaccination acceptance for their children, 3) vaccination acceptance if reccomended by 
one's employer or doctor, 4) COVID-19 mandate acceptance (required by: (a) employers and (b) the government and for (c) university students, (d) school children, and (e) indoor activities like auditoriums, concerts, sports events, and (f) international travel), 5) trust in central and local government, 6) experience of anxiety and depression (moderate; 3-4 days per week, or most or all of the time; 5-7 days), 7) COVID-19 experience (self or a family member became ill with COVID-19, lost a family member to COVID-19), and 8) demographic variables (age, gender, education, income, loss of income due to COVID-19 (self-reported as "moderate" or "severe"), and health care worker (HCW) status (Supplemental Information 1).

Data analysis

This study documents vaccine acceptance globally and by country at a point in time approximately six months after the first vaccine was authorized and made available for emergency use. First, vaccine acceptance was assessed using descriptive statistics. The association between a country's vaccine acceptance and current COVID-19 cases and mortality (per million population), COVIDSCORE-10 (June 2020), ${ }^{51}$ COVID-VAC score (June 2021), and vaccine hesitancy were each assessed using Pearson correlations. We also compared the acceptance of a hypothetical vaccine described in our June 2020 study and current COVID-19 vaccine acceptance now that vaccines are available. Weighted multivariable logistic regressions were used to assess the relationship between vaccine acceptance and socio-demographic variables, COVID-19 illness experience (personally or a family member), COVID-VAC score, trust in central and local government, and mental health. In addition to adult vaccine acceptance, we investigated attitudes regarding vaccination of children and requirements for proof of vaccination to travel internationally or to attend work, school, or indoor events using descriptive statistics. Finally, vaccine acceptance among HCWs was assessed across all countries combined. Statistical significance was set at alpha $=0.05$. Analyses were conducted in SAS 9.4 . 


\section{Author Contributions}

JVL, SCR and AEM conceived the study. PFF collected the data. KW was responsible for coding and data analyses with input from TMW. JVL, TMW, CAP and AEM wrote the first draft of the paper. JVL, AEM, TMW, CAP, KW, KR, SCR, JPL, and JH edited subsequent revisions of the draft and approved the final manuscript.

\section{Acknowledgements}

The authors would like to thank Patrick F Fox at Consensus Strategies for surveying the countries and reviewing the methodology.

\section{Competing Interests Statement}

The authors declare no competing interests.

\section{References}

1. World Health Organization. Ten threats to global health in 2019 [Internet]. 2019 [cited 2020 Oct 6]. Available from: https://www.who.int/news-room/spotlight/ten-threats-to-globalhealth-in-2019

2. Lazarus JV, Ratzan SC, Palayew A, Gostin LO, Larson HJ, Rabin K, et al. A global survey of potential acceptance of a COVID-19 vaccine. Nat Med [Internet]. 2020; Available from: https://www.nature.com/articles/s41591-020-1124-9

3. Mathieu E, Ritchie H, Ortiz-Ospina E, Roser M, Hasell J, Appel C, et al. A global database of COVID-19 vaccinations. Nat Hum Behav 202157 [Internet]. 2021 May 10 [cited 2021 Aug 3];5(7):947-53. Available from: https://www.nature.com/articles/s41562-021-01122-8

4. Stojanovic J, Boucher VG, Gagne M, Gupta S, Joyal-Desmarais K, Paduano S, et al. Global Trends and Correlates of COVID-19 Vaccination Hesitancy: Findings from the iCARE Study. Vaccines 2021, Vol 9, Page 661 [Internet]. 2021 Jun 17 [cited 2021 Jul 9];9(6):661. Available from: https://www.mdpi.com/2076-393X/9/6/661/htm

5. Boyon N. COVID-19 vaccination intent is decreasing globally [Internet]. Ipsos and World Economic Forum. 2020 [cited $2021 \mathrm{Jul}$ 29]. Available from: https://www.ipsos.com/en/globalattitudes-covid-19-vaccine-october-2020

6. Troiano G, Nardi A. Vaccine hesitancy in the era of COVID-19. Public Health. 2021 May 1;194:245-51.

7. Sallam M. COVID-19 Vaccine Hesitancy Worldwide: A Concise Systematic Review of Vaccine Acceptance Rates. Vaccines 2021, Vol 9, Page 160 [Internet]. 2021 Feb 16 [cited 2021 Jul 9];9(2):160. Available from: https://www.mdpi.com/2076-393X/9/2/160/htm

8. Grossman VA. The COVID-19 Vaccine: Why the Hesitancy? J Radiol Nurs. 2021 Jun 1;40(2):116-9.

9. Sallam M, Dababseh D, Eid H, Hasan H, Taim D, Al-Mahzoum K, et al. Low COVID-19 Vaccine Acceptance Is Correlated with Conspiracy Beliefs among University Students in Jordan. Int J 
Environ Res Public Health [Internet]. 2021 Mar 1 [cited 2021 Apr 29];18(5):2407. Available from: https://www.mdpi.com/1660-4601/18/5/2407

10. Loomba S, de Figueiredo A, Piatek SJ, de Graaf K, Larson HJ. Measuring the impact of COVID19 vaccine misinformation on vaccination intent in the UK and USA. Nat Hum Behav [Internet]. 2021 Mar 1 [cited 2021 Apr 28];5(3):337-48. Available from: https://doi.org/10.1038/s41562-021-01056-1

11. Chaccour C, Vilasanjuan R. Infodemic: How Has the Epidemic of Misinformation Affected the Response to COVID-19? ISGlobal. 2020.

12. Suzanna Awang B, Edlaine F de MV, Ching Sin S, Won Sun C, Supa P, M Tasdik H, et al. Factors Affecting COVID-19 Vaccine Acceptance: An International Survey among Low- and MiddleIncome Countries. Vaccines [Internet]. 2021 May 1 [cited 2021 Jul 9];9(5). Available from: https://pubmed.ncbi.nlm.nih.gov/34067682/

13. Our World in Data. Coronavirus (COVID-19) Vaccinations [Internet]. Statistics and Research. 2021 [cited 2021 Apr 20]. Available from: https://ourworldindata.org/covid-vaccinations

14. Lane S, MacDonald NE, Marti M, Dumolard L. Vaccine hesitancy around the globe: Analysis of three years of WHO/UNICEF Joint Reporting Form data-2015-2017. Vaccine. 2018 Jun 18;36(26):3861-7.

15. Cadeddu C, Daugbjerg S, Ricciardi W, Rosano A. Beliefs towards vaccination and trust in the scientific community in Italy. Vaccine [Internet]. 2020 Sep 29 [cited 2021 Jul 21];38(42):660917. Available from: https://pubmed.ncbi.nlm.nih.gov/32788138/

16. Palamenghi L, Barello S, Boccia S, Graffigna G. Mistrust in biomedical research and vaccine hesitancy: the forefront challenge in the battle against COVID-19 in Italy. Eur J Epidemiol [Internet]. 2020 Aug 1 [cited 2021 Jul 27];35(8):785-8. Available from: https://pubmed.ncbi.nlm.nih.gov/32808095/

17. May T. Anti-Vaxxers, Politicization of Science, and the Need for Trust in Pandemic Response. $J$ Health Commun [Internet]. 2020 [cited 2021 Jul 27];25(10):761-3. Available from: https://pubmed.ncbi.nlm.nih.gov/33345732/

18. Bicchieri C, Fatas E, Aldama A, Casas A, Deshpande I, Lauro M, et al. In science we (should) trust: Expectations and compliance across nine countries during the COVID-19 pandemic. PLoS One [Internet]. 2021 Jun 1 [cited 2021 Jul 21];16(6). Available from: https://pubmed.ncbi.nlm.nih.gov/34086823/

19. Veit W, Brown R, Earp B. In Science We Trust? Being Honest About the Limits of Medical Research During COVID-19. Am J Bioeth [Internet]. 2021 [cited 2021 Jul 27];21(1):22-4. Available from: https://pubmed.ncbi.nlm.nih.gov/33373581/

20. Funk C, Tyson A, Kennedy B, Johnson C. Science and Scientists Held in High Esteem Across Global Publics [Internet]. 2020 Sep [cited 2021 Jul 20]. Available from:

https://www.pewresearch.org/science/2020/09/29/science-and-scientists-held-in-highesteem-across-global-publics/

21. Arce JSS, Warren SS, Meriggi NF, Scacco A, McMurry N, Voors M, et al. COVID-19 vaccine acceptance and hesitancy in low- and middle-income countries. Nat Med 2021 [Internet]. $2021 \mathrm{Jul} 16$ [cited $2021 \mathrm{Jul} 27$ ];1-10. Available from: https://www.nature.com/articles/s41591-021-01454-y

22. Yaqub O, Castle-Clarke $S$, Sevdalis N, Chataway J. Attitudes to vaccination: A critical review. Soc Sci Med. 2014 Jul 1;112:1-11.

23. Paterson P, Meurice F, Stanberry LR, Glismann S, Rosenthal SL, Larson HJ. Vaccine hesitancy and healthcare providers. Vaccine [Internet]. 2016 Dec 20 [cited 2021 Apr 28];34(52):6700-6. Available from: https://pubmed.ncbi.nlm.nih.gov/27810314/

24. Verger $P$, et al. Vaccine Hesitancy Among General Practitioners and Its Determinants During Controversies: A National Cross-sectional Survey in France. EBioMedicine [Internet]. 2015 Aug 1 [cited 2021 Jul 27];2(8):891-7. Available from: https://pubmed.ncbi.nlm.nih.gov/26425696/

25. Biswas N, Mustapha T, Khubchandani J, Price JH. The Nature and Extent of COVID-19 
Vaccination Hesitancy in Healthcare Workers. J Community Health [Internet]. 2021 [cited 2021 Jul 9];1. Available from: /pmc/articles/PMC8056370/

26. Picchio CA, Carrasco MG, Sagué-Vilavella M, Rius C. Knowledge, attitudes and beliefs about vaccination in primary healthcare workers involved in the administration of systematic childhood vaccines, Barcelona, 2016/17. Eurosurveillance [Internet]. 2019 Feb 7 [cited 2021 May 20];24(6):1800117. Available from:

https://www.eurosurveillance.org/content/10.2807/1560-7917.ES.2019.24.6.1800117

27. Elizondo-Alzola U, Carrasco MG, Pinós L, Picchio CA, Rius C, Diez E. Vaccine hesitancy among paediatric nurses: Prevalence and associated factors. PLoS One [Internet]. 2021 May 1 [cited 2021 Jul 27];16(5):e0251735. Available from:

https://journals.plos.org/plosone/article?id=10.1371/journal.pone.0251735

28. Dzieciolowska S, Hamel D, Gadio S, Dionne M, Gagnon D, Robitaille L, et al. Covid-19 vaccine acceptance, hesitancy, and refusal among Canadian healthcare workers: A multicenter survey. Am J Infect Control. 2021 Apr 28;

29. Bauernfeind S, Hitzenbichler F, Huppertz G, Zeman F, Koller M, Schmidt B, et al. Brief report: attitudes towards Covid-19 vaccination among hospital employees in a tertiary care university hospital in Germany in December 2020. Infect 2021 [Internet]. 2021 May 20 [cited 2021 Aug 3];1:1-5. Available from: https://link.springer.com/article/10.1007/s15010-02101622-9

30. Soares P, Rocha JV, Moniz M, Gama A, Laires PA, Pedro AR, et al. Factors Associated with COVID-19 Vaccine Hesitancy. Vaccines [Internet]. 2021 Mar 22 [cited 2021 Jul 9];9(3):300. Available from: https://www.mdpi.com/2076-393X/9/3/300/htm

31. Siegrist $M$, Zingg $A$. The role of public trust during pandemics: Implications for crisis communication. Eur Psychol [Internet]. 2014 [cited 2020 Oct 6];19(1):23-32. Available from: /record/2013-34232-001

32. Ezeibe CC, Ilo C, Ezeibe EN, Oguonu CN, Nwankwo NA, Ajaero CK, et al. Political distrust and the spread of COVID-19 in Nigeria. https://doi.org/101080/1744169220201828987 [Internet]. 2020 Dec 1 [cited 2021 Jul 21];15(12):1753-66. Available from: https://www.tandfonline.com/doi/abs/10.1080/17441692.2020.1828987

33. Okereke M, Ukor NA, Adebisi YA, Ogunkola IO, lyagbaye EF, Owhor GA, et al. Impact of COVID-19 on access to healthcare in low- and middle-income countries: Current evidence and future recommendations. Int J Health Plann Manage [Internet]. 2021 Jan 1 [cited 2021 Jul 26];36(1):13-7. Available from: https://onlinelibrary.wiley.com/doi/full/10.1002/hpm.3067

34. Acharya KP, Ghimire TR, Subramanya SH. Access to and equitable distribution of COVID-19 vaccine in low-income countries. npj Vaccines [Internet]. $2021 \mathrm{Apr} 14$ [cited $2021 \mathrm{Jul}$ 9];6(1):1-3. Available from: https://www.nature.com/articles/s41541-021-00323-6

35. Murphy J, Vallières F, Bentall RP, Shevlin M, McBride O, Hartman TK, et al. Psychological characteristics associated with COVID-19 vaccine hesitancy and resistance in Ireland and the United Kingdom. Nat Commun [Internet]. 2021 Dec 1 [cited 2021 May 5];12(1):1-15. Available from: https://doi.org/10.1038/s41467-020-20226-9

36. Qian Y, Fan W. Who loses income during the COVID-19 outbreak? Evidence from China. Res Soc Stratif Mobil. 2020 Aug 1;68:100522.

37. Ettman C, Abdalla S, Cohen G, Sampson L, Vivier P, Galea S. Prevalence of Depression Symptoms in US Adults Before and During the COVID-19 Pandemic. JAMA Netw open [Internet]. 2020 Sep 3 [cited 2021 Jul 9];3(9). Available from: https://pubmed.ncbi.nlm.nih.gov/32876685/

38. Hossain M, Tasnim S, Sultana A, Faizah F, Mazumder H, Zou L, et al. Epidemiology of mental health problems in COVID-19: a review. F1000Research [Internet]. 2020 [cited 2021 Jul 9];9. Available from: https://pubmed.ncbi.nlm.nih.gov/33093946/

39. García-Iglesias J, Gómez-Salgado J, Martín-Pereira J, Fagundo-Rivera J, Ayuso-Murillo D, Martínez-Riera J, et al. Impacto del SARS-CoV-2 (Covid-19) en la salud mental de los 
profesionales sanitarios: una revisión sistemática. Rev Esp Salud Publica [Internet]. 2020 [cited $2021 \mathrm{Jul}$ 9];94(1):e1-20. Available from: https://medes.com/publication/152295

40. Vindegaard N, Benros M. COVID-19 pandemic and mental health consequences: Systematic review of the current evidence. Brain Behav Immun [Internet]. 2020 Oct 1 [cited 2021 Jul 9];89:531-42. Available from: https://pubmed.ncbi.nlm.nih.gov/32485289/

41. Mazereel V, Assche K Van, Detraux J, Hert M De. COVID-19 vaccination for people with severe mental illness: why, what, and how? The Lancet Psychiatry [Internet]. 2021 May 1 [cited 2021 Jul 9];8(5):444-50. Available from:

http://www.thelancet.com/article/S2215036620305642/fulltext

42. Bendau A, Plag J, Petzold MB, Ströhle A. COVID-19 vaccine hesitancy and related fears and anxiety. Int Immunopharmacol [Internet]. 2021 Aug 1 [cited 2021 Jul 9];97:107724. Available from: https://www.ncbi.nlm.nih.gov/pmc/articles/PMC8078903/

43. Jefsen $\mathrm{OH}, \mathrm{K} \emptyset \mathrm{lbæk} \mathrm{P}$, Gil Y, Speed M, Dinesen PT, Sønderskov KM, et al. COVID-19 vaccine willingness amongst patients with mental illness compared with the general population. Acta Neuropsychiatr [Internet]. 2021 [cited 2021 Jul 9];1-4. Available from:

https://www.cambridge.org/core/journals/acta-neuropsychiatrica/article/abs/covid19vaccine-willingness-amongst-patients-with-mental-illness-compared-with-the-generalpopulation/949CE2ADF019A3D78F64E704146EE348

44. Lin C, Tu P, Beitsch LM. Confidence and receptivity for covid-19 vaccines: A rapid systematic review. Vaccines [Internet]. 2021 Jan 1 [cited 2021 Apr 20];9(1):1-32. Available from: https://pubmed.ncbi.nlm.nih.gov/33396832/

45. Islam M, Kamal A, Kabir A, Southern D, Khan S, Hasan S, et al. COVID-19 vaccine rumors and conspiracy theories: The need for cognitive inoculation against misinformation to improve vaccine adherence. PLoS One [Internet]. 2021 May 1 [cited 2021 Jul 19];16(5). Available from: https://pubmed.ncbi.nlm.nih.gov/33979412/

46. Murphy M, Nanadiego FA, McCavera L, Nichols C, Kalekas P, Wachs D. Assessing the Validity and Accuracy of Online Videos on Vaccine Health Risks. Clin Pediatr (Phila) [Internet]. 2020 Feb 19 [cited $2021 \mathrm{Jul} 9$ ];59(4-5):458-66. Available from: https://journals.sagepub.com/doi/abs/10.1177/0009922820905866

47. Eibensteiner F, Ritschl V, Nawaz F, Fazel S, Tsagkaris C, Kulnik S, et al. People's Willingness to Vaccinate Against COVID-19 Despite Their Safety Concerns: Twitter Poll Analysis. J Med Internet Res [Internet]. 2021 Apr 1 [cited 2021 Jul 9];23(4). Available from: https://pubmed.ncbi.nlm.nih.gov/33872185/

48. Smith DT, Attwell K, Evers U. Support for a COVID-19 vaccine mandate in the face of safety concerns and political affiliations: An Australian study: Politics [Internet]. 2021 May 7 [cited 2021 Jul 9]; Available from: https://journals.sagepub.com/doi/10.1177/02633957211009066

49. Largent EA, Persad G, Sangenito S, Glickman A, Boyle C, Emanuel EJ. US Public Attitudes Toward COVID-19 Vaccine Mandates. JAMA Netw Open [Internet]. 2020 Dec 18 [cited 2021 Jul 9];3(12). Available from: https://www.ncbi.nlm.nih.gov/pmc/articles/PMC7749443/

50. Dubov A, Phung C. Nudges or mandates? The ethics of mandatory flu vaccination. Vaccine [Internet]. 2015 May 21 [cited 2021 Jul 9];33(22):2530-5. Available from: https://pubmed.ncbi.nlm.nih.gov/25869886/

51. Lazarus JV, Ratzan S, Palayew A, Billari FC, Binagwaho A, Kimball S, et al. COVID-SCORE: A global survey to assess public perceptions of government responses to COVID-19 (COVIDSCORE-10). Hotchkiss D, editor. PLoS One. 2020 Oct;15(10):e0240011.

52. Worldometer. COVID-19 data [Internet]. 2020 [cited 2020 Jun 30]. Available from: https://www.worldometers.info/coronavirus/about/\#sources

53. Lazarus JV, Binagwaho A, El-Mohandes A, Fielding JE, Larson HJ, Plasència A, et al. Keeping governments accountable: the COVID-19 Assessment Scorecard (COVID-SCORE). Nat Med [Internet]. 2020 Jun 11 [cited 2020 Jun 19];1-4. Available from: https://doi.org/10.1038/s41591-020-0950-0 
54. White TM, Cash-Gibson L, Martin-Moreno JM, Matesanz R, Crespo J, Alfonso-Sanchez JL, et al. COVID-SCORE Spain: Public perceptions of key government COVID-19 control measures. Eur J Public Health [Internet]. 2021 Apr 19 [cited 2021 May 3]; Available from:

https://academic.oup.com/eurpub/advance-article/doi/10.1093/eurpub/ckab066/6238158

55. Larson HJ, Cooper LZ, Eskola J, Katz SL, Ratzan S. Addressing the vaccine confidence gap. Lancet. 2011;378(9790):526-35.

56. MacDonald NE, SAGE Working Group on Vaccine Hesitancy. Vaccine hesitancy: Definition, scope and determinants. Vaccine [Internet]. 2015 Aug 14 [cited 2020 Oct 6];33(34):4161-4. Available from: https://pubmed.ncbi.nlm.nih.gov/25896383/

57. Larson HJ, Clarke RM, Jarrett C, Eckersberger E, Levine Z, Schulz WS, et al. Measuring trust in vaccination: A systematic review. Hum Vaccines Immunother [Internet]. 2018 Jul 3 [cited 2021 Apr 22];14(7):1599-609. Available from: /pmc/articles/PMC6067893/

58. Quinn SC, Parmer J, Freimuth VS, Hilyard KM, Musa D, Kim KH. Exploring communication, trust in government, and vaccination intention later in the $2009 \mathrm{H} 1 \mathrm{~N} 1$ pandemic: Results of a national survey. Biosecurity and Bioterrorism [Internet]. 2013 Jun 1 [cited 2020 Jul 9];11(2):96-106. Available from: http://www.knowledgenetworks.com

59. Karafillakis E, Larson HJ. The benefit of the doubt or doubts over benefits? A systematic literature review of perceived risks of vaccines in European populations. Vaccine [Internet]. 2017 Sep 5 [cited 2021 Apr 22];35(37):4840-50. Available from:

https://pubmed.ncbi.nlm.nih.gov/28760616/

60. Strategic Advisory Group of Experts on Immunization (SAGE). Report of the SAGE Working Group on Vaccine Hesitancy [Internet]. Geneva; 2014 Oct [cited 2021 Apr 28]. Available from: https://www.who.int/immunization/sage/meetings/2014/october/1_Report_WORKING_GR OUP_vaccine_hesitancy_final.pdf 
Tables and figures

Table 1. Sample characteristics

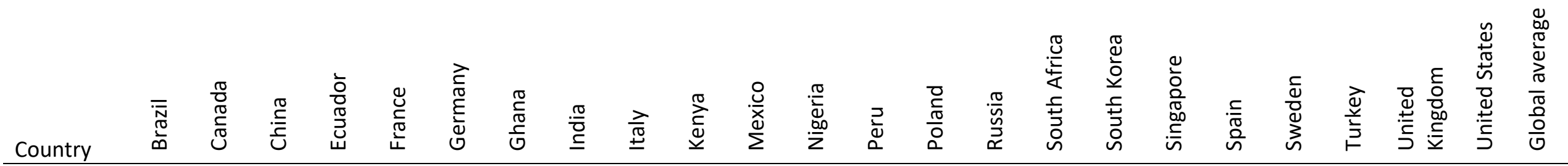

$\begin{array}{lllllllllllllllllllllllllllllllllll} & \% & \% & \% & \% & \% & \% & \% & \% & \% & \% & \% & \% & \% & \% & \% & \% & \% & \% & \% & \% & \% & \% & \% & \end{array}$

\begin{tabular}{|c|c|c|c|c|c|c|c|c|c|c|c|c|c|c|c|c|c|c|c|c|c|c|c|c|}
\hline & $\%$ & $\%$ & $\%$ & $\%$ & $\%$ & $\%$ & $\%$ & $\%$ & $\%$ & $\%$ & $\%$ & $\%$ & $\%$ & $\%$ & $\%$ & $\%$ & $\%$ & $\%$ & $\%$ & $\%$ & $\%$ & $\%$ & $\%$ & $\%$ \\
\hline \multicolumn{25}{|l|}{ Age } \\
\hline \multicolumn{25}{|l|}{ Groups } \\
\hline $18-29$ & 19 & 16.5 & 16.5 & 23.5 & 16.5 & 14.1 & 35.6 & 24.2 & 18.5 & 37.9 & 23.5 & 31.9 & 23.3 & 16 & 15.8 & 25 & 18.4 & 20.7 & 15.5 & 15.7 & 22.1 & 16.6 & 17.1 & 21.0 \\
\hline 30-39 & 20.3 & 17.7 & 22.4 & 22.1 & 15.2 & 15.3 & 64.4 & 21.2 & 20 & 20.7 & 22.1 & 68.1 & 21.5 & 17.3 & 17.7 & 23.4 & 21.3 & 20.7 & 17.4 & 16.3 & 20.6 & 17.2 & 15.8 & 23.4 \\
\hline $40-49$ & 19 & 16.5 & 23.5 & 22.1 & 16.5 & 16.5 & & 21.2 & 20 & 18.9 & 20.6 & & 20.6 & 18.5 & 19 & 20.3 & 19.9 & 22 & 18.6 & 17.6 & 20.6 & 17.8 & 17.1 & 19.3 \\
\hline $50-59$ & 24.1 & 16.5 & 16.5 & 14.7 & 17.7 & 17.6 & & 16.7 & 16.9 & 13.8 & 16.2 & & 16.5 & 17.3 & 18.7 & 17.2 & 18.4 & 17.1 & 17.4 & 15.7 & 17.6 & 16.6 & 18.4 & 17.2 \\
\hline $60+$ & 17.7 & 32.9 & 21.2 & 17.6 & 34.2 & 36.5 & & 16.7 & 24.6 & 8.8 & 17.6 & & 18 & 30.9 & 28.8 & 14.1 & 22 & 19.5 & 31.1 & 34.7 & 19.1 & 31.8 & 31.6 & 24.3 \\
\hline \multicolumn{25}{|l|}{ Sex } \\
\hline Male & 49.1 & 49.3 & 51.5 & 49.7 & 49.2 & 48.9 & 50.6 & 50.4 & 48.7 & 49.3 & 49.8 & 50.5 & 49.4 & 48.1 & 46.2 & 48.9 & 49.8 & 49.3 & 48.9 & 49.6 & 48.7 & 49.1 & 48.9 & 49.3 \\
\hline Female & 50.9 & 50.1 & 48.5 & 49.7 & 50.7 & 50.5 & 49.2 & 48 & 51 & 49.9 & 50.1 & 49.2 & 49.9 & 51.5 & 53.2 & 50.6 & 49.7 & 50.2 & 50.7 & 49.6 & 49.9 & 50.4 & 51 & 50.2 \\
\hline $\begin{array}{l}\text { Prefer not } \\
\text { to } \\
\text { say/Other }\end{array}$ & & 0.6 & & 0.6 & 0.1 & 0.6 & 0.2 & 1.6 & 0.3 & 0.8 & 0.1 & 0.3 & 0.7 & 0.4 & 0.6 & 0.5 & 0.4 & 0.5 & 0.4 & 0.7 & 1.4 & 0.5 & 0.1 & 0.54 \\
\hline \multicolumn{25}{|c|}{ Education (university degree) } \\
\hline No & 82.6 & 73.8 & 88 & 88 & 82 & 75 & 85 & 91 & 85.6 & 97 & 84 & 91.5 & 84 & 75 & 45 & 92.5 & 44.9 & 67.8 & 67 & 75.7 & 79 & 65.6 & 64.3 & 77.6 \\
\hline Yes & 17.4 & 26.2 & 12 & 12 & 18 & 25 & 15 & 9 & 14.4 & 3 & 16 & 8.5 & 16 & 25 & 55 & 7.5 & 55.1 & 32.2 & 33 & 24.3 & 21 & 34.4 & 35.7 & 38.7 \\
\hline
\end{tabular}

Income (country median)

More

than

Median 


\begin{tabular}{|c|c|c|c|c|c|c|c|c|c|c|c|c|c|c|c|c|c|c|c|c|c|c|c|c|}
\hline $\begin{array}{l}\text { Less than } \\
\text { Median }\end{array}$ & 58.2 & 53 & 29.3 & 36.7 & 53.2 & 61.1 & 42.8 & 19.4 & 57.8 & 28.2 & 42.4 & 48 & 38.9 & 53.4 & 69.3 & 18.9 & 37.4 & 54.1 & 52.3 & 68.8 & 56.9 & 49 & 46.1 & 46.7 \\
\hline $\begin{array}{l}\text { No } \\
\text { income }\end{array}$ & 9.7 & 7.2 & 4.9 & 33 & 7.2 & 8.7 & 39.5 & 14 & 12.4 & 35.7 & 8 & 34.1 & 20.3 & 6.4 & 6.3 & 15.5 & 12.2 & 10.4 & 10 & 8.6 & 10.8 & 8 & 11.9 & 14.6 \\
\hline
\end{tabular}

\section{Have you or anyone else in your household experienced a loss in income due to}

the COVID-19 pandemic?

Severe

loss

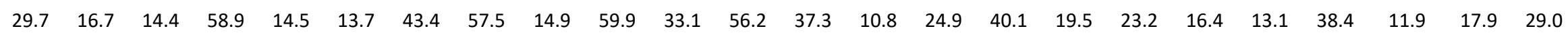

Moderate

loss

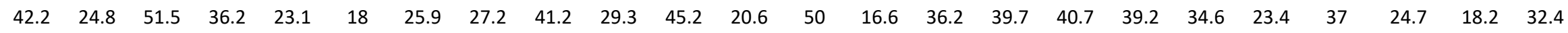

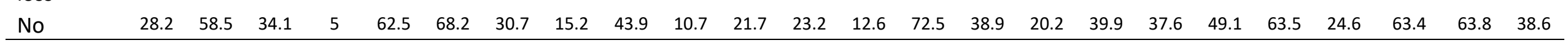

COVID-19 experience

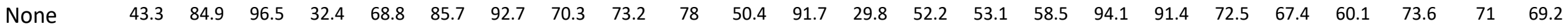
Self/famil

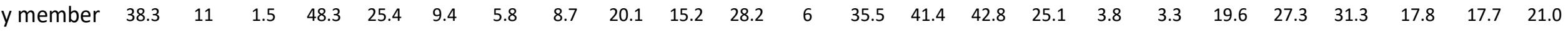
sick

Lost

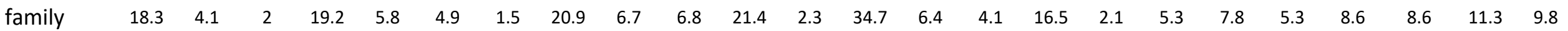
member

Health care worker

$\begin{array}{lllllllllllllllllllllllll}\text { Yes } & 5.5 & 9.8 & 9 & 7.7 & 10.8 & 12 & 20.6 & 25.4 & 5.6 & 10.9 & 8.9 & 19.4 & 8.2 & 4.7 & 2.9 & 6.7 & 11.2 & 7.7 & 7.8 & 13.8 & 9.3 & 14.8 & 16.5 & 10.8\end{array}$

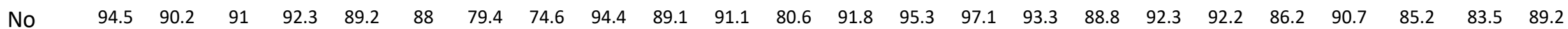

Mental health

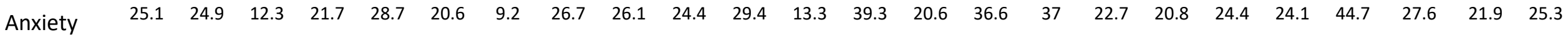

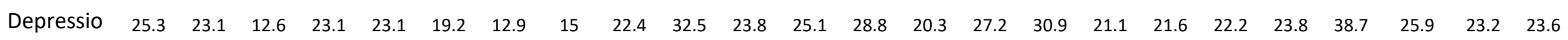

Note: Anxiety and depression defined as symptoms moderate amount of time (3-4 days) or most or all of the time (5-7 days). 
○ เ
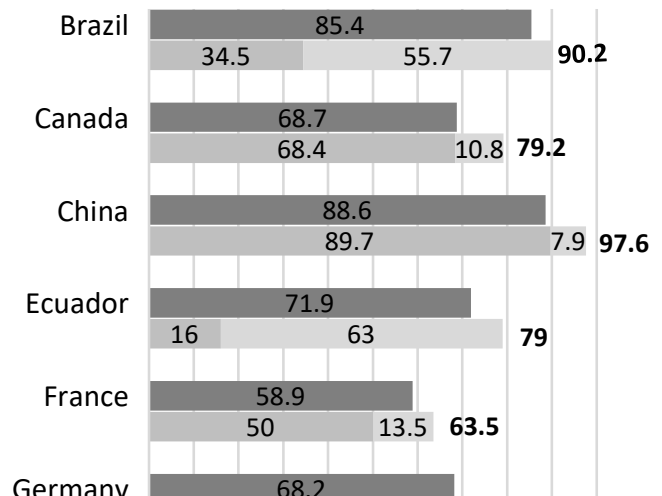

taly

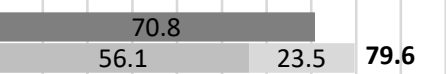

Ghana

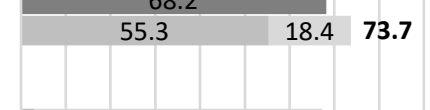

$$
\text { Kenya }
$$

79.6

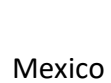

2

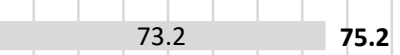

Mexico

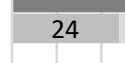

.2

Nigeria

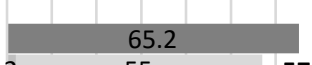

ru

55

57

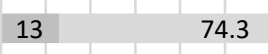

87.3

Poland
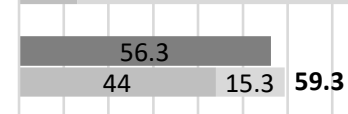

Russia

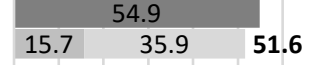

South Africa

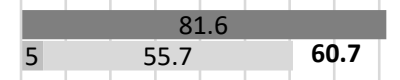

South Korea
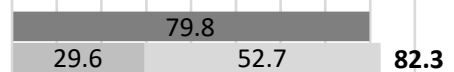

Singapore

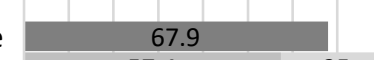

82.3

产

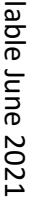



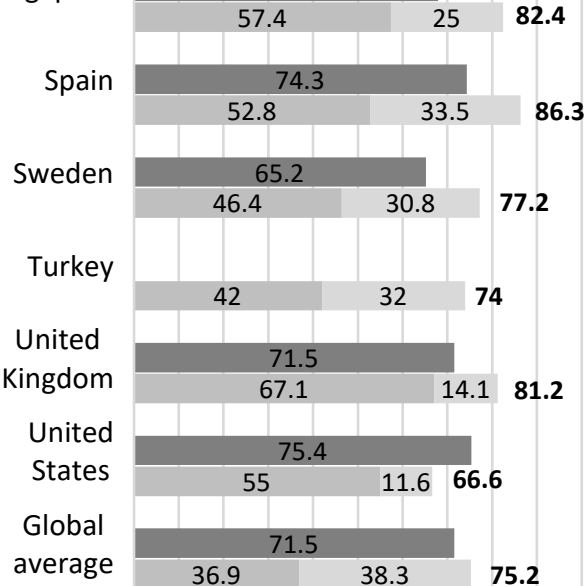


- June 2020: I would follow my employer's recommendation to get a COVID-19 vaccine once the government has approved it as safe and effective.

June 2021: I will take the COVID-19 vaccine if my employer recommends it.

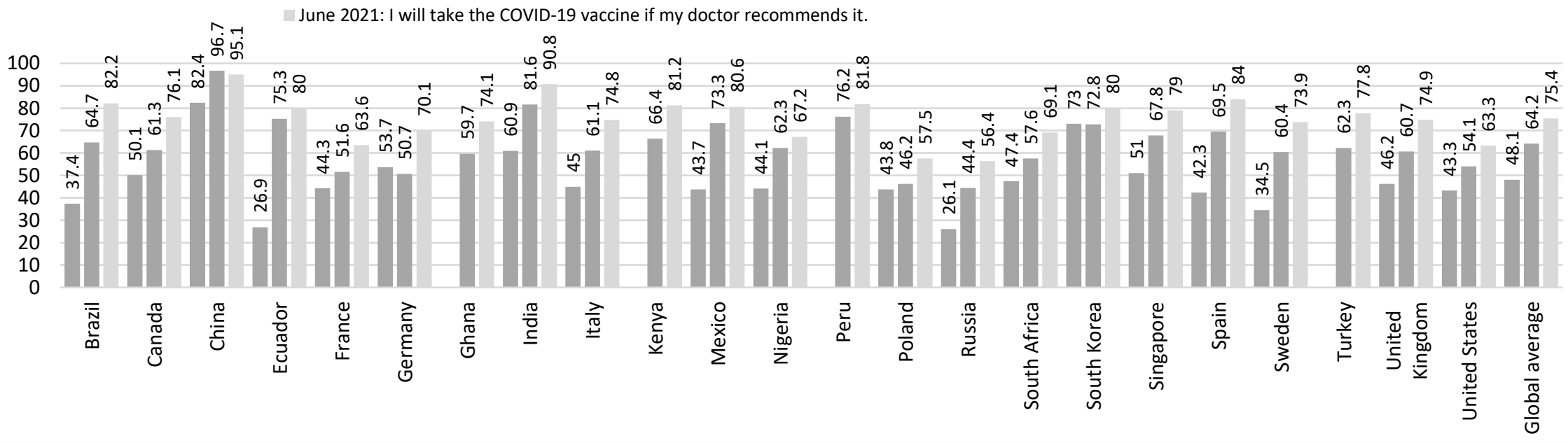

Panel c. Vaccine acceptance if recommended by employer or one's doctor among 1) willing to get vaccinated, 2) unsure/unwilling to get vaccinated. 


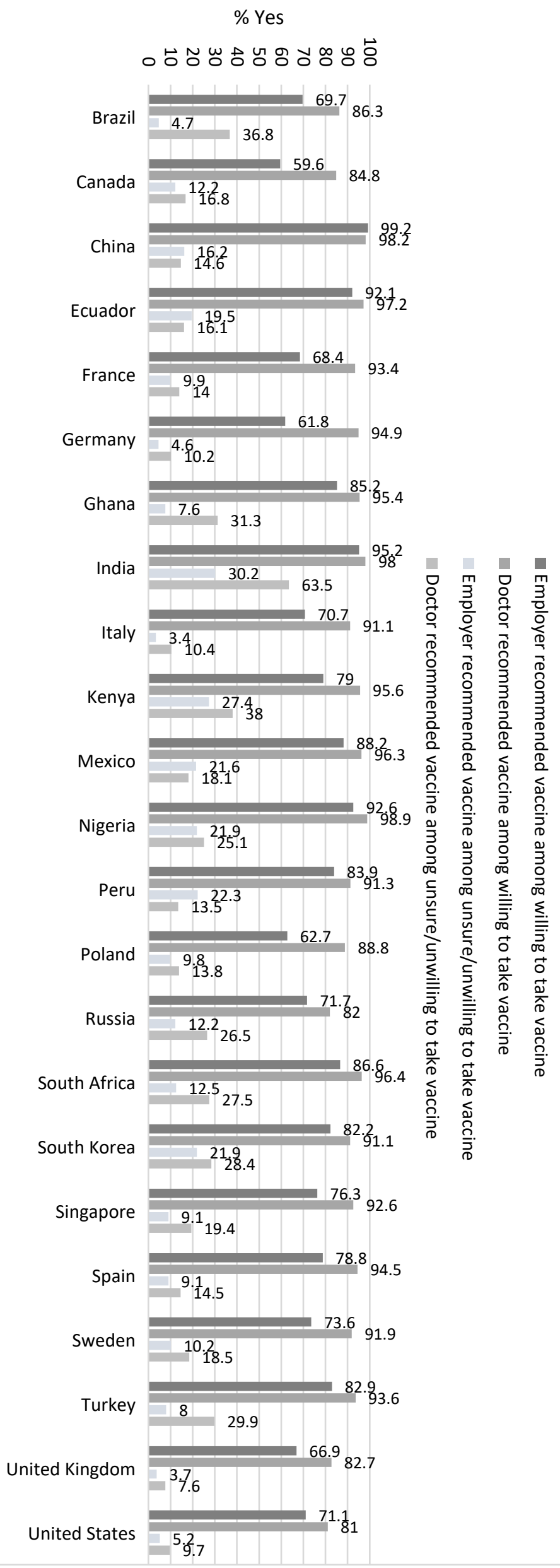


Figure 2. Vaccine acceptance by current cases and mortality

Panel a. Vaccine acceptance and COVID-19 cases

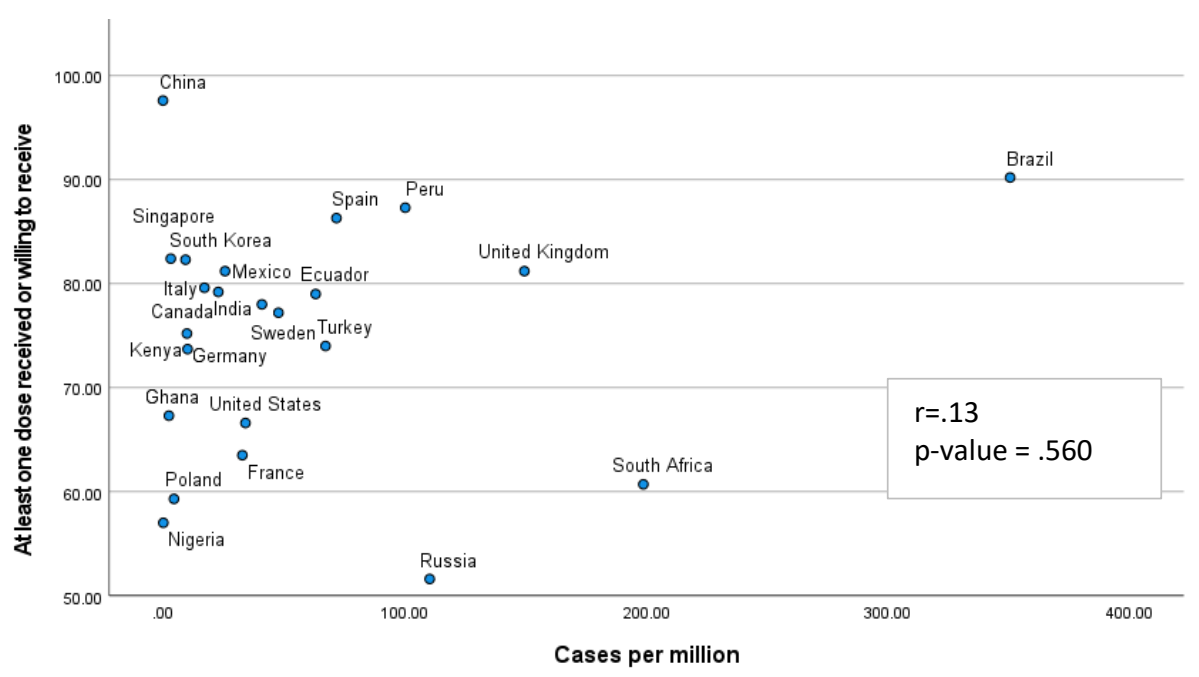

Panel b. Vaccine acceptance and COVID-19 mortality

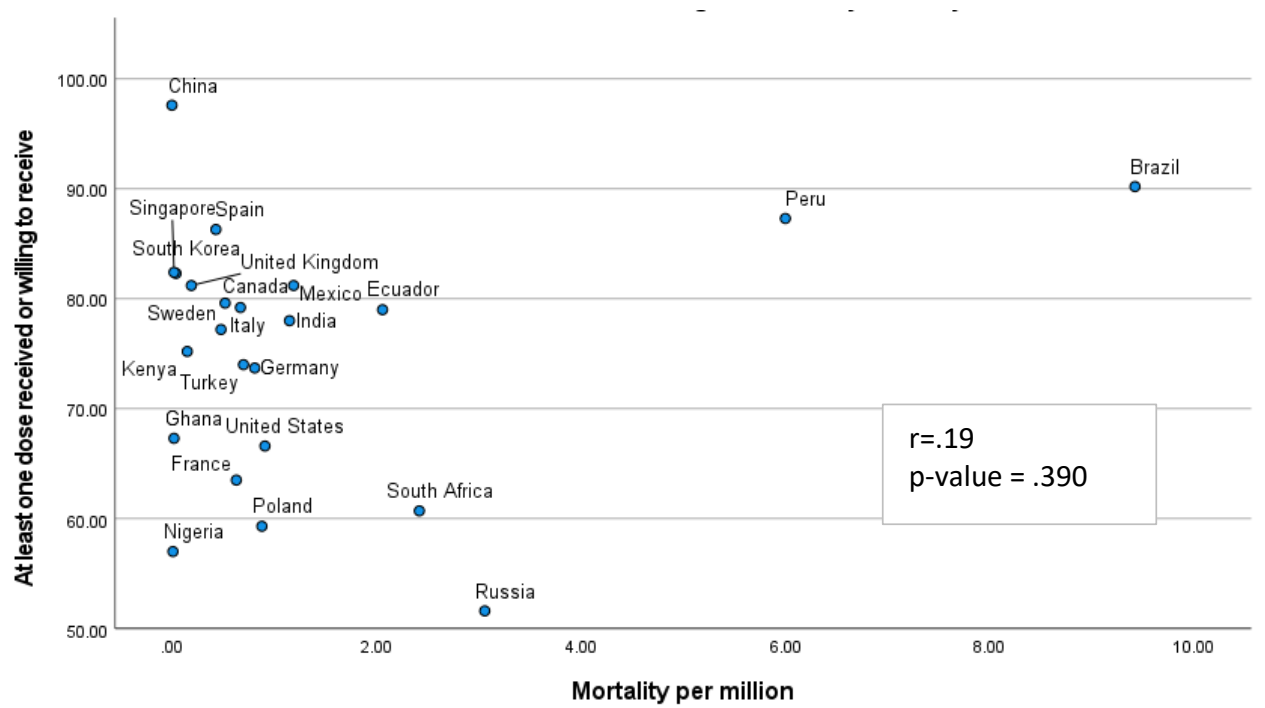


Panel c. Vaccine acceptance and COVID-SCORE-10 (June 2020)

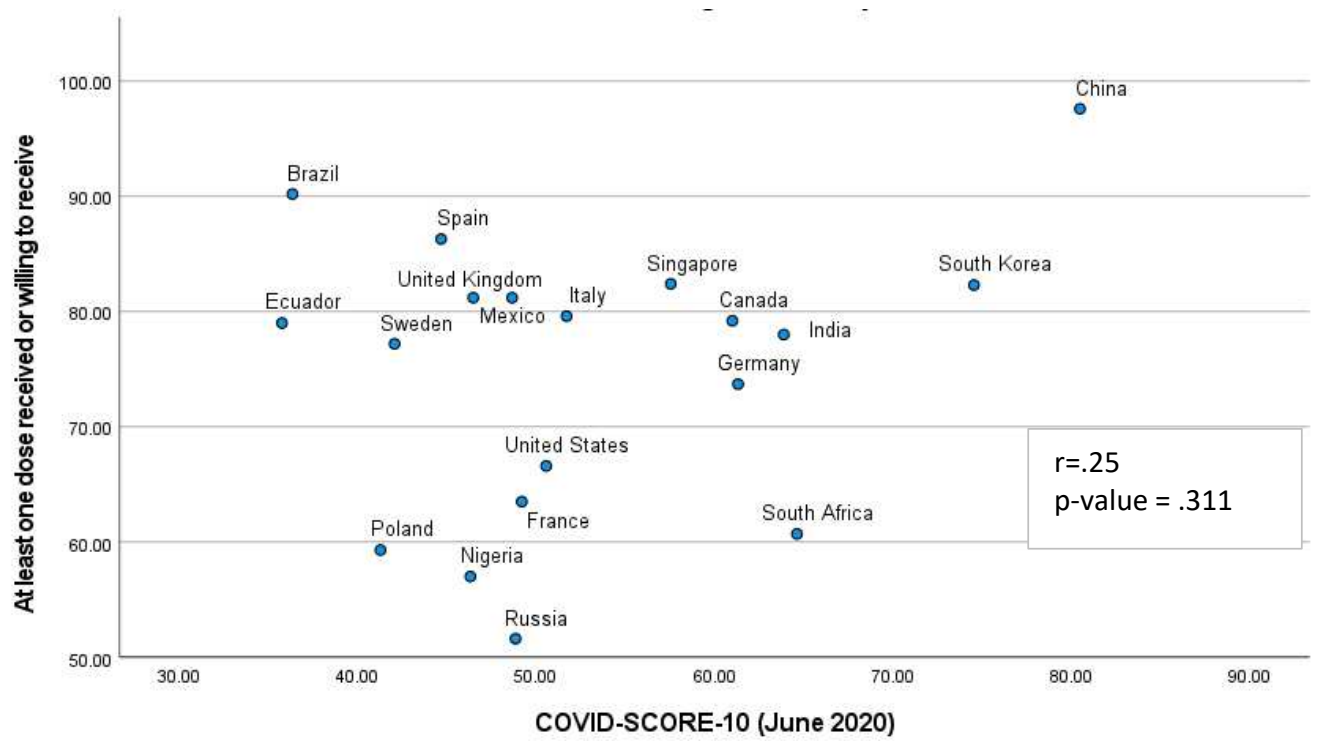

Panel d. Vaccine acceptance and COVID-VAC

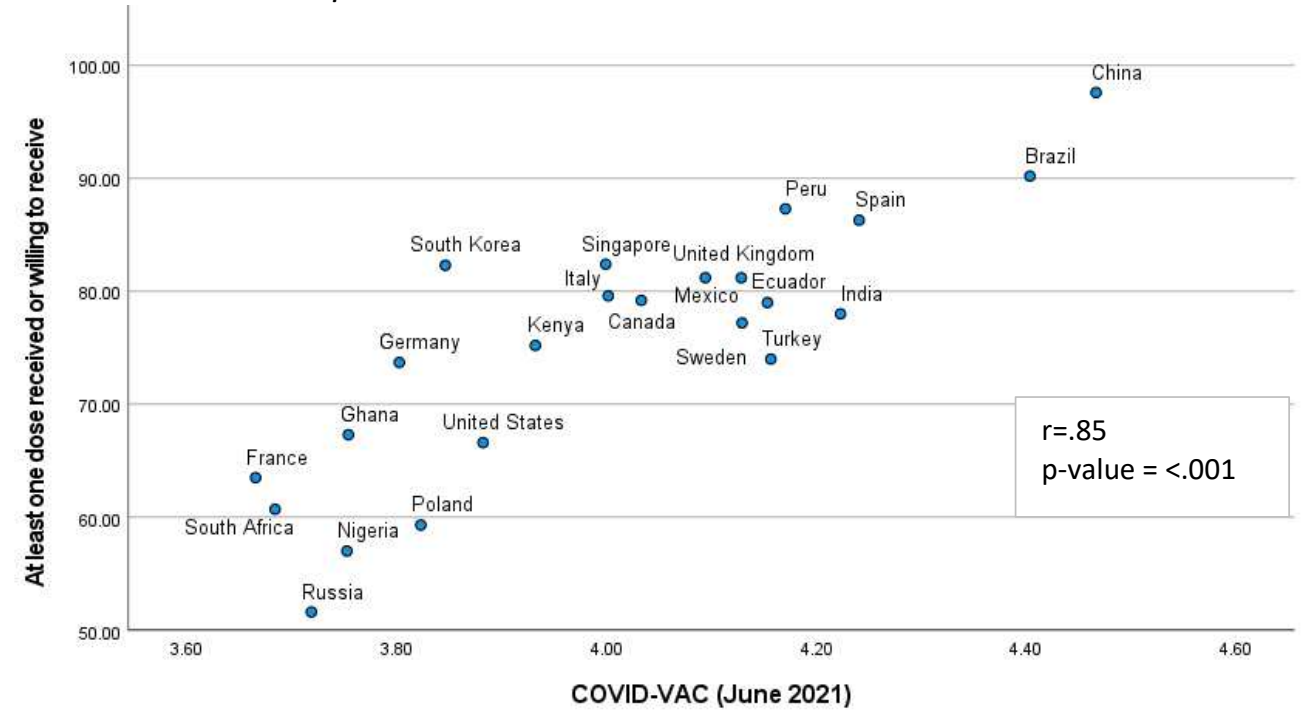


Panel e. Vaccination rates and hesitancy

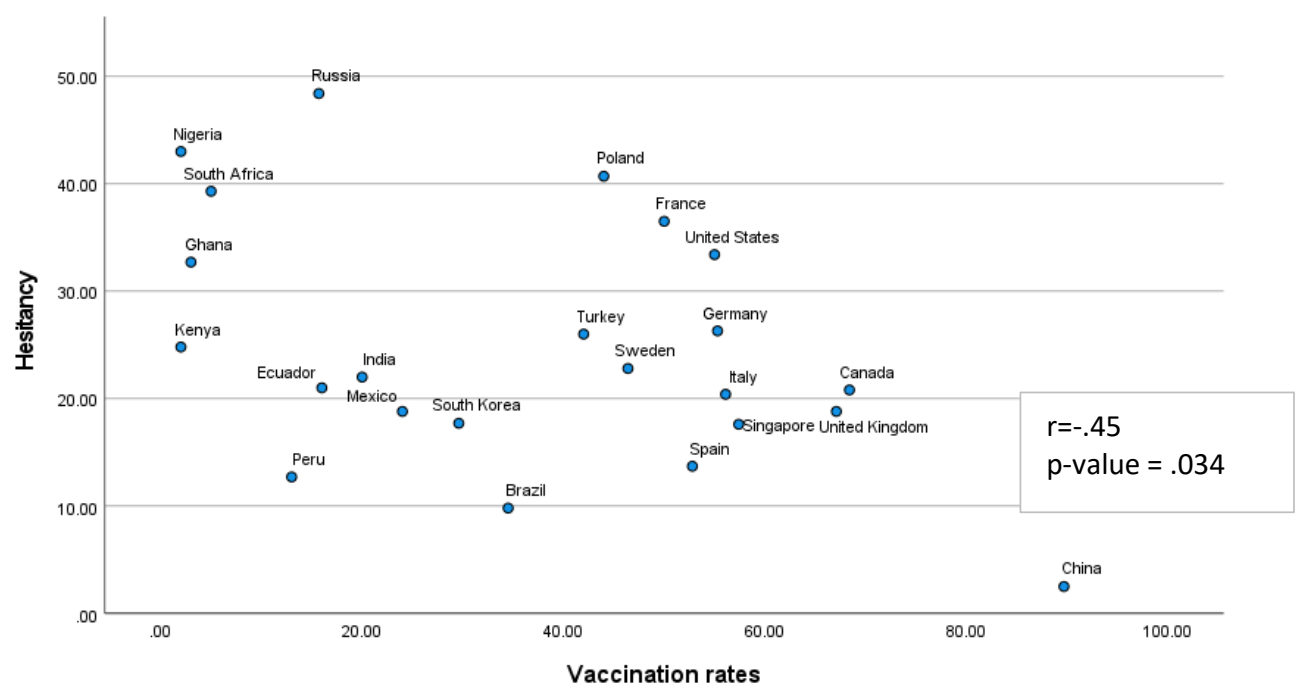

Figure 3. Vaccine acceptance for children among parents

\section{Panel a. Overall}

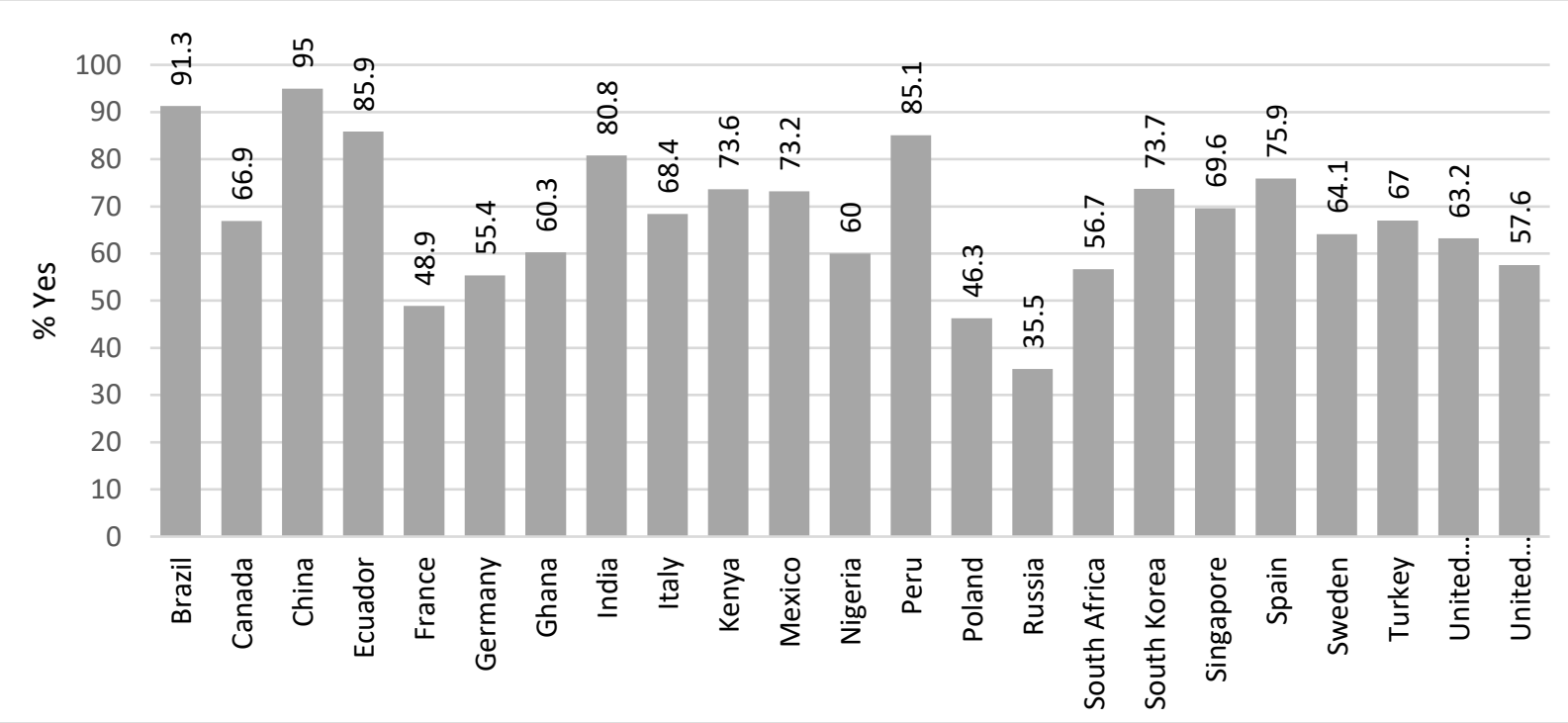

Panel b. By respondent's willingness to vaccinate self. 


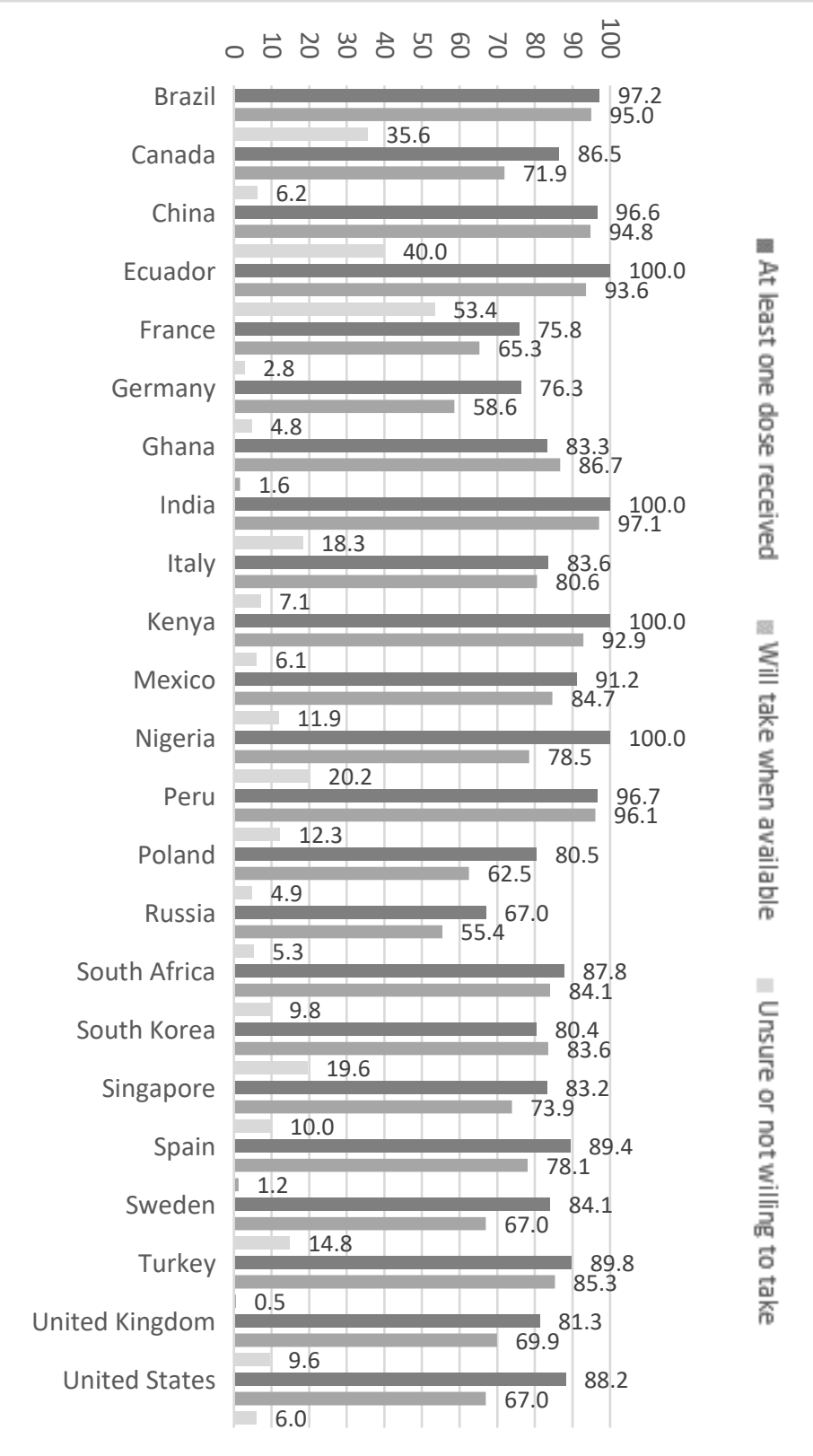


Figure 4. Correlates of vaccine acceptance-sociodemographic factors and COVID-19 experience.

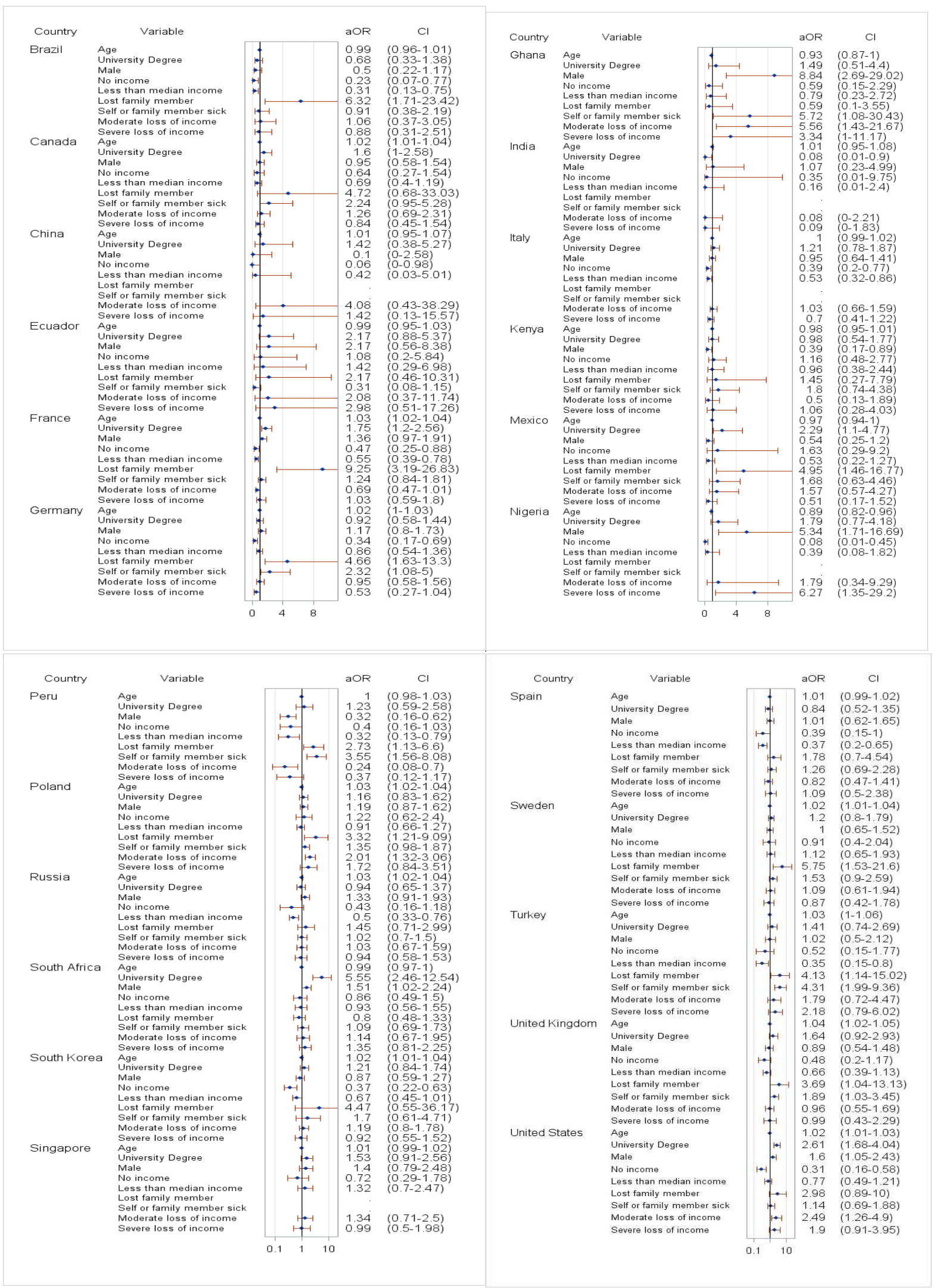

Adjusted odds ratios ( $\mathrm{aOR}$ ) and $95 \% \mathrm{Cl}$ (log scale) from weighted multivariable logistic regression; refrence categories: Female, No university degree, More than median income, No COVID-19 sickness/death, No loss of income. 
Figure 5. Correlates of vaccine acceptance-COVID-VAC score, trust in government, anxiety and depression.
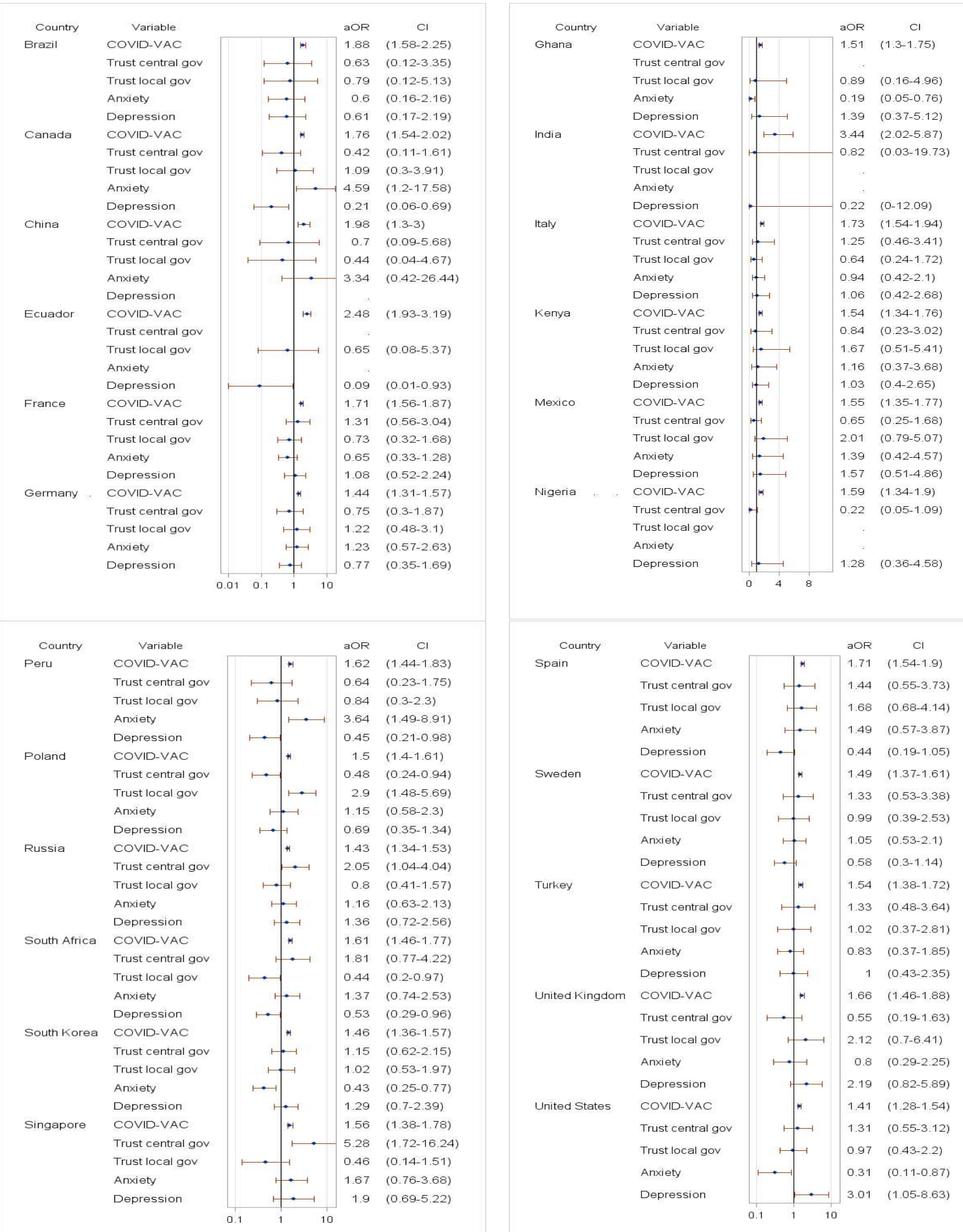

Adjusted odds ratios (aOR) and $95 \% \mathrm{Cl}$ (log scale) from weighted multivariable logistic regression, adjusted for socio-demographic factors and COVID-19 experience. 
Table 2. Vaccine acceptance by HCW status.

\begin{tabular}{l|c|c|c|c|c|c|c|}
\hline & & \multicolumn{2}{|c|}{$\begin{array}{c}\text { At least Will take } \\
\text { one } \\
\text { dose } \\
\text { received }\end{array}$} & $\begin{array}{c}\text { At least one } \\
\text { available } \\
\text { dose received } \\
\text { or will receive } \\
\text { when available }\end{array}$ & $\begin{array}{c}\text { Unsure } \\
\text { or not } \\
\text { willing to } \\
\text { take }\end{array}$ & & \\
\hline & $\mathrm{n}$ & $\%$ & $\%$ & $\%$ & $\%$ & p-value & aOR(95\%Cl \\
\hline Not HCW & 19840 & 52 & 31 & 83 & 17 & & \\
\hline All HCW & 3295 & 72.4 & 19.4 & 91.8 & 8.1 & $<.001$ & $1.72(1.38,2.13)$ \\
\hline Physician & & & & & & & \\
\hline Nurse & 891 & $85.6^{\mathrm{a}}$ & $11.2^{\mathrm{a}}$ & $96.9^{\mathrm{a}}$ & $3.1^{\mathrm{a}}$ & $<.001$ & \\
\hline Community Health Worker & 619 & $74.5^{\mathrm{b}}$ & $19.1^{\mathrm{b}}$ & $93.5^{\mathrm{b}}$ & $6.5^{\mathrm{b}}$ & & \\
\hline Other healthcare worker & 790 & $69.6^{\mathrm{b}}$ & $22.5^{\mathrm{b}}$ & $92.2^{\mathrm{b}}$ & $7.8^{\mathrm{b}}$ & & \\
\hline p-Value based & 995 & $61.6^{\mathrm{c}}$ & $24.5^{\mathrm{b}}$ & $86.1^{\mathrm{c}}$ & $13.9^{\mathrm{c}}$ & & \\
\hline
\end{tabular}

p-value based on Chi-squared tests. Different subscripts denote statistically significant pairwise differences. aOR from multivariate logistic model after adjusting for demographic variables, COVID19 experience and clustering of HWC in countries. 
Figure 6. Vaccine mandates acceptance.

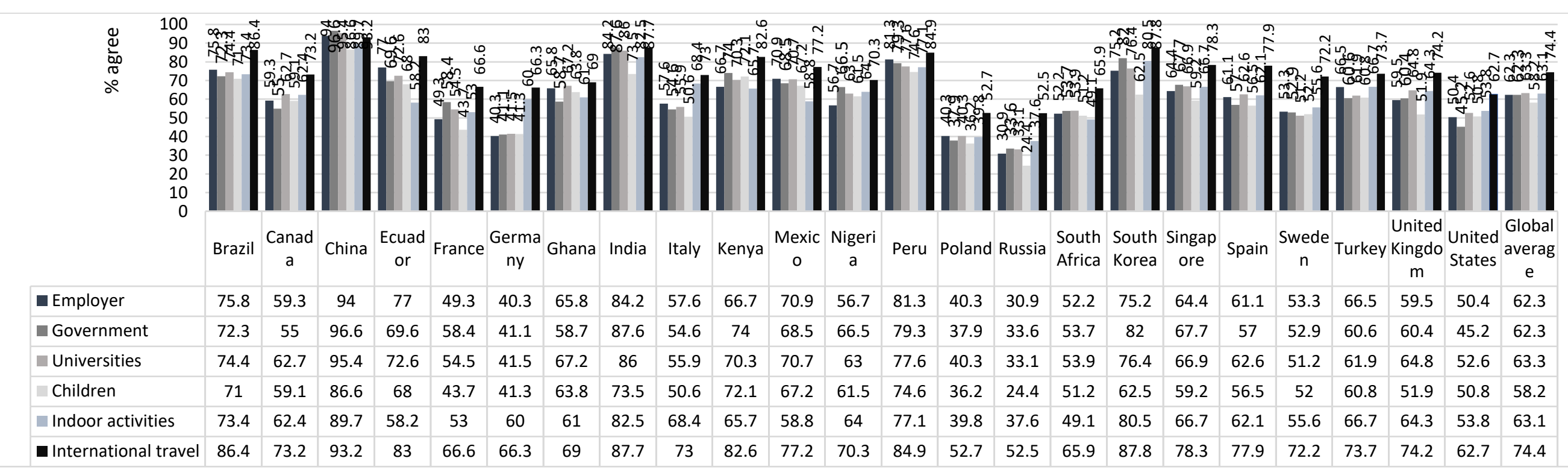




\section{Supplementary Files}

This is a list of supplementary files associated with this preprint. Click to download.

- SupplementalMaterialsubmit.docx 